\title{
Kinetics of Procalcitonin in the Management of Small Bowel Obstruction: A Preliminary Report
}

\author{
Cosse C ${ }^{1,2}$, Sabbagh $C^{1,2}$, Rebibo L'1, Grelpois $\mathbf{G}^{1}$, Galmiche A $^{2,3}$ and Regimbeau JM ${ }^{1,4, *}$ \\ ${ }^{1}$ Department of Digestive and Metabolic Surgery, Amiens North Hospital, University of Picardie, Amiens, France \\ ${ }^{2}$ Inserm U1088, Jules Verne University of Picardie, Amiens, France \\ ${ }^{3}$ Department of biochemistry, Amiens South Hospital, University of Picardie, Amiens, France \\ ${ }^{4}$ EA4294, Jules Verne University of Picardie, Amiens, France
}

\section{Abstract}

Background: Small Bowel Obstruction (SBO) is mainly due to adhesions acquired after abdominal surgery. Its management could be conservative or surgical but the choice is difficult because of the absence of clinico-biological markers. Serum procalcitonin (PCT) has previously been proposed as a biomarker. The aim was to present the kinetics' profiles of serum PCT in cases of Conservative Management (CM) success and surgical management (SM) in patients with SBO.

Study design: From January to October 2013, 59 patients with adhesion-related SBO were included in a prospective, monocenter, non-randomized, clinical study. PCT was measured during 3 days maximum (or until the transit was restored), every six hours. The patients were divided into subgroups (conservative (CM) and surgical management (SM)). The predictive time points were identified with ROC curves.

Results; Patients in CM group ( $n=47$ ) presented at admission a lower PCT and a higher chloride than in the SM group $(n=12)(p<0.003)$. The time points of PCT for predicting SM are at admission (threshold $>0.165 \mathrm{ng} / \mathrm{mL}$; sensitivity $(\mathrm{Se})=83.3 \%$ and negative predictive value (NPV)=93\%), 18 hours after admission (threshold $>0.275 \mathrm{ng} / \mathrm{mL} ; \mathrm{Se}=100 \%$ and $\mathrm{NPV}=100 \%$ ) and 24 hours after admission (threshold $>0.255 \mathrm{ng} / \mathrm{mL} ; \mathrm{Se}=83.3 \%$ and $\mathrm{NPV}=95 \%$ ).

Conclusion: PCT is helpful in SBO's management. The more predictive time points are at admission, 18 hours and 24 hours after admission to identify the patients requiring surgery.

Keywords: Procalcitonin; Kinetics; Small bowel obstruction

Abbreviations: SBO: Small Bowel Obstruction; PCT: Procalcitonin, CM: Conservative Management; SM: Surgical Management; Se: Sensitivity; Sp: Specificity; PPV: Positive Predictive Value; NPV: Negative Predictive Value; AUC: Area Under The Curve; ROC: Receiver Operating Curve; SD: Standard Deviation

\section{Introduction}

Small Bowel Obstruction (SBO) is a major health problematic that is responsible for between $1 \%$ and $3 \%$ of emergency department admissions [1-3] and 75\% of all obstructions. The main aetiology for SBO is adhesions (65-75\%) [4] acquired after abdominal surgery (in $67 \%$ to $93 \%$ of all cases, depending on the series) $[4,5]$. The treatment of SBO is based on two distinct approaches: conservative management with nasogastric tube suction or Surgical Management (SM) if there are clinical signs of intestinal ischemia [6] or if Conservative Management (CM) fails [7-8].

The main challenge in SBO management is to propose the more appropriate treatment for each patient. The difficulty for discriminate between the two options lies on the absence of accurate-enough clinico-biomarker. Our team previously proposed the use of serum Procalcitonin (PCT), precursor of calcitonin [9] first described in 1993 by Assicot et al. [10]. In this series we showed that serum procalcitonin could discriminate on the one side between the conservative and the surgical management with a threshold of $0.17 \mathrm{ng} / \mathrm{mL}$ and on the other between patients surgically managed with or without peroperative bowel ischemia with a threshold of $0.57 \mathrm{ng} / \mathrm{mL}$ [11]. However, no team reports the kinetics of PCT in SBO.

The objectives of the present study were i. to present the kinetics' profiles of serum PCT in cases of CM success and Surgical Management (SM), ii. to identify the more predictive time points to discriminate between CM success and SM and iii. to validate the predictive value of PCT in case of preoperatively confirmed bowel ischemia.

\section{Materials and Methods}

\section{Population}

From January to October 2013, 59 patients with adhesion-related $\mathrm{SBO}$ were included in a prospective, monocenter, non-randomized, clinical study (PCT kinetics' study). The inclusion criteria were SBO diagnosed with CT scan and a clinical examination. The exclusion criteria were early postoperative obstruction, obstruction with neoplasia, obstruction with inflammatory bowel disease, colon obstruction, a history of abdominal radiotherapy, the presence of pneumoperitoneum, clinical signs of infection, age under 18, pregnancy, guardianship. Small bowel obstruction was diagnosed on the presence of standard clinical signs (abdominal pain, tenderness, nausea or vomiting, no passage of gas and/or stools) and radiological signs (presence of air fluid levels, dilated bowel loops) possibly secondary to an abdominal surgery.

The PCT kinetics' study participants were divided into two groups: patients in whom the CM was successful (the CM group, $n=47$ ) and those in whom it had failed (the SM group, $n=12$ ).

*Corresponding author: Regimbeau JM, Department of Digestive, oncologica and metabolic Surgery, CHU Nord Amiens and University of Picardie, Place Victor Pauchet F-80054 Amiens cedex 01, France, Tel: +33 (0)3 226683 01; Fax: +33 (0)3 226686 80; E-mail: regimbeau.jean-marc@chu-amiens.fr

Received February 24, 2014; Accepted March 20, 2014; Published April 05, 2014

Citation: Cosse C, Sabbagh C, Rebibo L, Grelpois G, Galmiche A, et al. (2014) Kinetics of Procalcitonin in the Management of Small Bowel Obstruction: A Preliminary Report. Surgery Curr Res 4: 184. doi:10.4172/2161-1076.1000184

Copyright: ( 2014 Cosse C, et al. This is an open-access article distributed under the terms of the Creative Commons Attribution License, which permits unrestricted use, distribution, and reproduction in any medium, provided the original author and source are credited. 


\section{Management}

Initially, each patient was managed conservatively with nasogastric tube suction. If renewed passage of gas and stools was observed, the nasogastric tube was clamped and removed; oral nutrition was resumed and the $\mathrm{CM}$ was considered to be a success. When faced with clinical signs (such as fever, abdominal pain) or biological signs (hyperleucocytosis i.e. leucocyte count $\geq 16 \times 10^{3} / \mathrm{mL}$ ) and the absence of gas 48 hours after the initiation of $\mathrm{CM}$, the conservative approach was considered to be a failure and the patient was scheduled for surgery.

\section{Surgery}

The open surgical procedure consisted in gut viscerolysis and (in some cases in presence of ischemia) bowel resection. An anastomosis was created depending of local conditions. In each case, the presence or absence of intra-operative bowel ischemia or necrosis was noted. Any adherences were described by the surgeon and noted in the patient's case report form.

\section{Study design}

The PCT kinetics' study's primary endpoint was to present the kinetics' profiles of serum PCT in cases of CM success and SM. The secondary endpoints were the identification of the more predictive time points to discriminate between CM success and SM and the predictive value of PCT for bowel ischemia. The study's patient disposition is shown in Figure 1.

The following items of patient data were collected: demographic information, laboratory blood test results (white blood cell count, platelet count, $\mathrm{C}$ reactive protein, urea, lactate, ions, ASAT, ALAT, and PCT), comorbidities (diabetes, hypertension, chronic kidney disease or

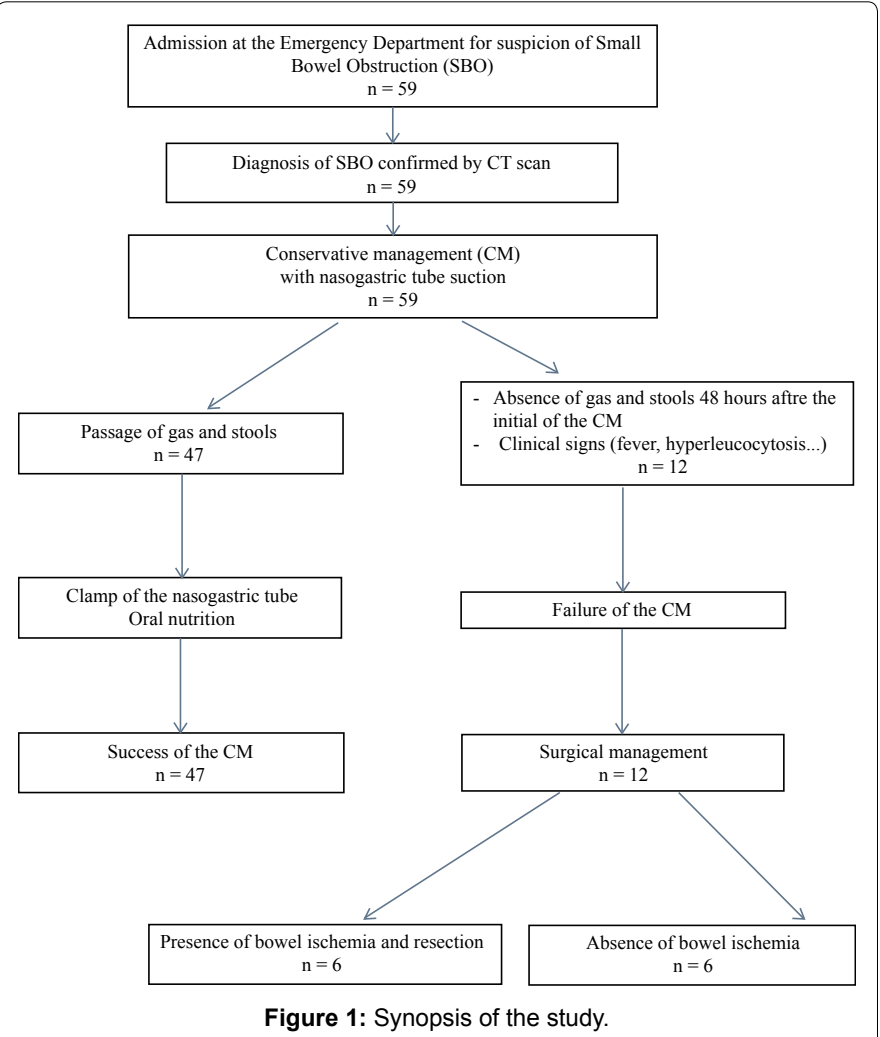

angor), and the history of abdominal surgery. Data related to surgical management included surgical recommendations, intra-operative signs and the surgical technique.

\section{The procalcitonin assay}

For each included patient, PCT test had been done on serum samples and measured on arrival to the emergency department and in the digestive surgery department during 3 days maximum (or until the transit was restored), every six hours. The Kryptor ${ }^{\circledR}$ T.R.A.C.E ${ }^{\circledR}$ assay (B.R.A.H.M.S, Clichy, France), routine laboratory test, was used onsite in the Biochemical laboratory. The reference value for PCT is $<0.5$ $\mathrm{ng} / \mathrm{mL}$.

\section{Statistical analysis}

Data are expressed as mean \pm Standard Deviation $(\mathrm{SD})$ or median (minimum - maximum) or number (percentage of patients). Univariate analyses were performed with the chi-squared test or Fisher's exact test for qualitative variables and the Student $t$ test for quantitative variables.

The threshold for statistical significance was set to $p \leq 0.05$. To identify the more predictive time points of PCT we generated Receiver Operating Characteristic (ROC) curves and calculated the area under the ROC curve (AUROCC). The predictive time points were presented with the sensitivity (Se), specificity (Sp), Positive Predictive Value (PPV), Negative Predictive Value (NPV) and the threshold. Statistical analysis was performed with SAS 9.2 (SAS Institute Inc., Cary, NC, USA) and PASW 18 (SPSS INC., Chicago, IL, USA).

\section{Results}

\section{Baseline characteristics of the population}

The characteristics of the population are shown Table 1. There is an imbalance between the CM and SM groups in terms of PCT $(\mathrm{p}=0.002)$ and Chloride $(\mathrm{p}=0.003)$ i.e. patients in $\mathrm{CM}$ group presented at admission a lower PCT and a higher chloride than in the SM group.

\section{Kinetics' profiles of serum PCT}

The kinetics' profiles of serum PCT and the evolution of the ratio between PCT in the CM and SM are presented respectively in Figures 2 and 3. The PCT levels are always lower in the CM group than in the $\mathrm{SM}$ one. The ratio between PCT measured in the CM and SM groups is comprised between 2 and 4 during the first 36 hours after the admission, and is high as 20 at 48 hours. The rate of CM failure considering the PCT values is depicted in Figure 4. This rate is correlated $\left(\mathrm{R}^{2}=0.989\right)$ with the serum PCT of which values correspond to the 2-folded; 3 -folded and 4-folded predictive threshold at admission.

\section{Predictive time points of PCT to discriminate between CM success and SM}

At admission: Using a ROC curve, the AUROCC for PCT at admission and SM was 0.802 [95\% CI, 0.65-0.954] (Figure 5). A PCT threshold $>0.165 \mathrm{ng} / \mathrm{mL}$ for predicting $\mathrm{SM}$ yielded a sensitivity of $83.3 \%$, a specificity of $61 \%$, a PPV of $35.7 \%$ and an NPV of $93.3 \%$.

18 hours after the admission: Using a ROC curve, the AUROCC for PCT 18 hours after the admission and SM was 0.89 [95\% CI, $0.0-1]$ (Figure 6). A PCT threshold $>0.275 \mathrm{ng} / \mathrm{mL}$ for predicting SM yielded a sensitivity of $100 \%$, a specificity of $75 \%$, a PPV of $30 \%$ and an NPV of $100 \%$. 
Citation: Cosse C, Sabbagh C, Rebibo L, Grelpois G, Galmiche A, et al. (2014) Kinetics of Procalcitonin in the Management of Small Bowel Obstruction: A Preliminary Report. Surgery Curr Res 4: 184. doi:10.4172/2161-1076.1000184

Page 3 of 6

\begin{tabular}{|c|c|c|c|}
\hline Variable & Conservative management $(n=47)$ & Surgical management $(n=12)$ & $P$ value \\
\hline Mean age, years (min - max) & $65(24-98)$ & $76(19-98)$ & 0.15 \\
\hline Male sex, $n(\%)$ & $20(43)$ & $4(33)$ & 0.56 \\
\hline Mean body mass index, $\mathrm{Kg} / \mathrm{m}^{2}(\min -\max )$ & $29(20-62)$ & $25(21-33)$ & 0.10 \\
\hline Diabetes, n (\%) & $3(6)$ & $1(8)$ & 0.81 \\
\hline Cancer, n (\%) & $13(28)$ & $3(25)$ & 0.85 \\
\hline Hypertension, $\mathbf{n}(\%)$ & $19(40)$ & $5(42)$ & 0.94 \\
\hline Dyslipidemia, n (\%) & $10(21)$ & $1(8)$ & 0.30 \\
\hline Peripheral vascular disease, $n$ (\%) & $6(13)$ & $0(0)$ & 0.19 \\
\hline Cardiopathy, n (\%) & $9(19)$ & $2(17)$ & 0.84 \\
\hline Acute kidney disease, $\mathbf{n}(\%)$ & $3(7)$ & $1(8)$ & 0.81 \\
\hline Smoker, n (\%) & $8(17)$ & $1(8)$ & 0.46 \\
\hline Chronic obstructive pulmonary disease, $\mathbf{n}(\%)$ & $3(7)$ & $1(8)$ & 0.81 \\
\hline Appendectomy, n (\%) & $12(26)$ & $4(33)$ & 0.59 \\
\hline Cholecystectomy, n (\%) & $8(17)$ & $2(17)$ & 0.98 \\
\hline Peritonitis, n (\%) & $2(4)$ & $1(8)$ & 0.57 \\
\hline Previous history of SBO, n (\%) & $5(11)$ & $0(0)$ & 0.24 \\
\hline Hernia, n (\%) & $5(11)$ & $0(0)$ & 0.24 \\
\hline Haemoglobin, g/dL \pm SD & $14 \pm 1.8$ & $14 \pm 2.7$ & 0.96 \\
\hline Leukocytes, $\times 10^{3} / \mathrm{mm}^{3} \pm \mathrm{SD}$ & $12 \pm 5.1$ & $11 \pm 6.9$ & 0.81 \\
\hline Platelets, $\times 10^{3} / \mathrm{mm}^{3} \pm$ SD & $310 \pm 100$ & $299 \pm 133$ & 0.81 \\
\hline C reactive protein, $\mathrm{mg} / \mathrm{L} \pm \mathrm{SD}$ & $31 \pm 40$ & $54 \pm 72$ & 0.31 \\
\hline ALAT, UI/L \pm SD & $31 \pm 22$ & $48 \pm 33$ & 0.15 \\
\hline ASAT, UI/L \pm SD & $29 \pm 19$ & $34 \pm 25$ & 0.59 \\
\hline Urea, $\mathrm{mmol} / \mathrm{L} \pm \mathrm{SD}$ & $8 \pm 6$ & $14 \pm 7$ & 0.49 \\
\hline Lactates, $\mathrm{mmol} / \mathrm{L} \pm \mathrm{SD}$ & $2.1 \pm 1$ & $2.9 \pm 1.6$ & 0.26 \\
\hline Amylase, UI/L \pm SD & $73 \pm 55$ & $75 \pm 33$ & 0.91 \\
\hline Lipase, UI/L I SD & $48 \pm 50$ & $60 \pm 28$ & 0.39 \\
\hline Sodium, mmol/L \pm SD & $138 \pm 3$ & $134 \pm 7$ & 0.09 \\
\hline Potassium, $\mathrm{mmol} / \mathrm{L} \pm \mathrm{SD}$ & $4 \pm 1$ & $4 \pm 1$ & 0.28 \\
\hline Chloride, $\mathrm{mmol} / \mathrm{L} \pm \mathrm{SD}$ & $101 \pm 5$ & $95 \pm 10$ & 0.003 \\
\hline Calcium, mmol/L \pm SD & $2.21 \pm 0.2$ & $2.20 \pm 0.2$ & 0.84 \\
\hline Phosphorus, mmol/L \pm SD & $1.06 \pm 0.3$ & $1.19 \pm 0.34$ & 0.25 \\
\hline Procalcitonin, ng/mL \pm SD & $0.16 \pm 0.14$ & $1.23 \pm 2.3$ & 0.002 \\
\hline
\end{tabular}

Table 1: Baseline characteristics of the population.

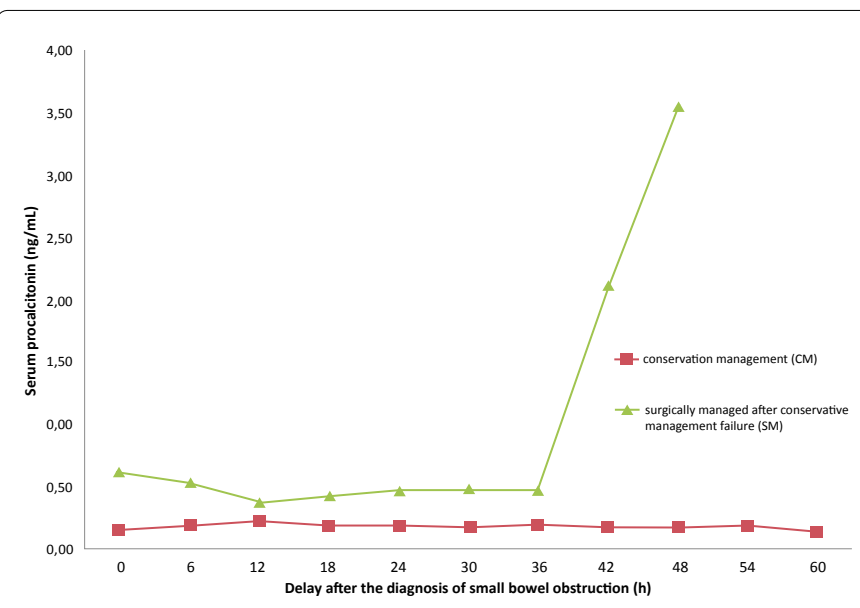

Figure 2: Kinetics' profiles of serum procalcitonin (PCT) in case of conservative (CM) and surgical management (SM)

24 hours after the admission: Using a ROC curve, the AUROCC for PCT 24 hours after the admission and SM was 0.859 [95\% CI, $0.692-1]$ (Figure 7). A PCT threshold $>0.255 \mathrm{ng} / \mathrm{mL}$ for predicting SM yielded a sensitivity of $83.3 \%$, a specificity of $73 \%$, a PPV of $42 \%$ and an NPV of $95 \%$.

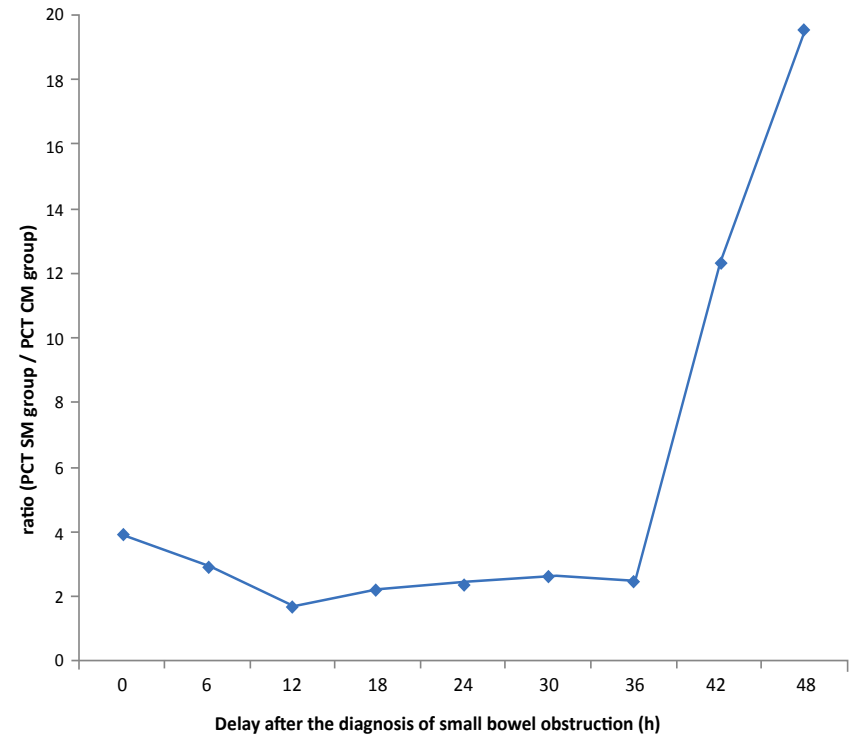

Figure 3: Ratio of PCT measurement between the $\mathrm{CM}$ and $\mathrm{SM}$ groups considering the delay after the diagnosis of small bowel obstruction. 


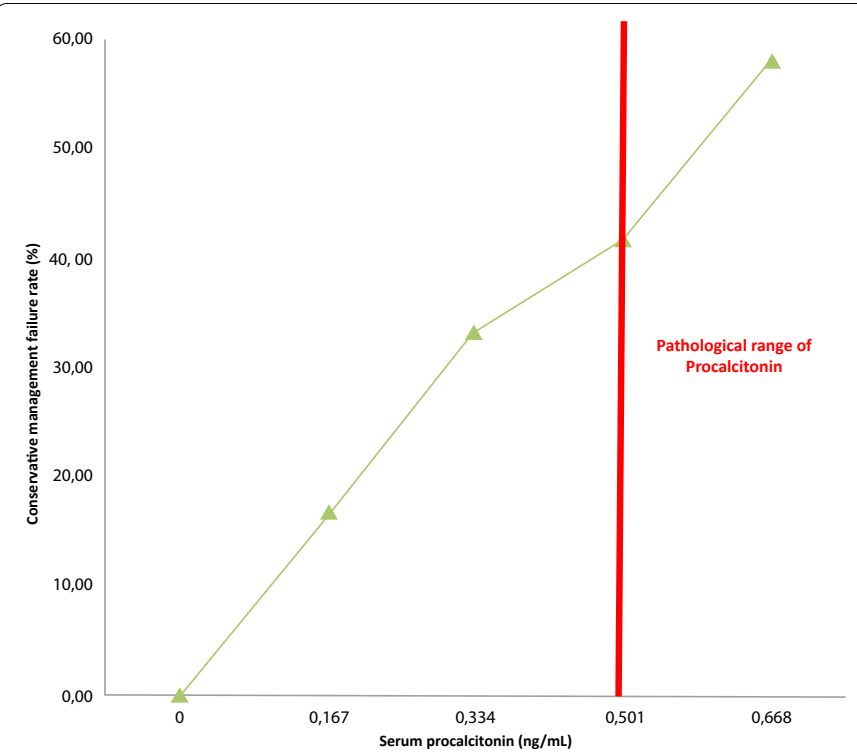

Figure 4: Rate of the conservative management failure considering the procalcitonin levels at admission.

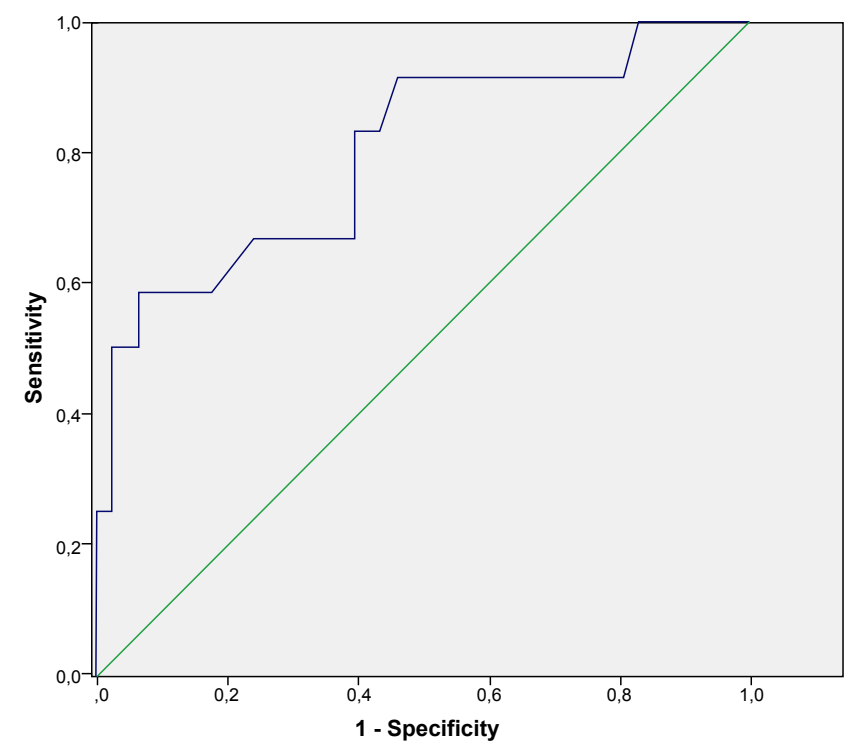

Figure 5: ROC curve for predicting the failure of the conservative management at admission.

Predictive time points of PCT to discriminate between SM without peroperative ischemia and $S M$ with peroperative ischemia

Using a ROC curve, the AUROCC for PCT and SM with peroperative ischemia was 0.861 [95\% CI, 0.641 - 1] (Figure 8). A PCT threshold $>0.53 \mathrm{ng} / \mathrm{mL}$ for predicting SM yielded a sensitivity of $80 \%$, a specificity of $84.8 \%$, a PPV of $40 \%$ and an NPV of $90.7 \%$.

\section{Discussion}

Our study was designed to complete our previous data related on the management of SBO and the potential use of serum PCT as a biomarker. The interest of PCT kinetics' study has been to validate our previous data in an independent cohort. Indeed, the present population is similar in terms of demographic data as those we previously analyzed [11]. Even if the inclusion period and duration are not similar (34 months vs. 10 months) there is no imbalance between the patients' characteristics (same age, same comorbidities). As we have already reported, at admission the threshold used to discriminate between conservative management's success and failure is around $0.17 \mathrm{ng} / \mathrm{mL}$ meaning normal PCT levels. This concordance between the results of these two studies could be explained as follow: first the laboratory that made the assessment has already been involved in the previous study (same material, same technicians, and same techniques); secondly as Steinbach et al. have reported in their article [12] the intra-assay and inter-assay coefficients of variation for the Kryptor T.R.A.C.E ${ }^{\circledR}$ method were below $5 \%$ and below $10 \%$, respectively. The pertinence of this method (quick results, repeatable data) now used daily in the clinical practice and emergency situations, made it sure and reliable.

The complexity for the surgeon to operate the patient is laid on the

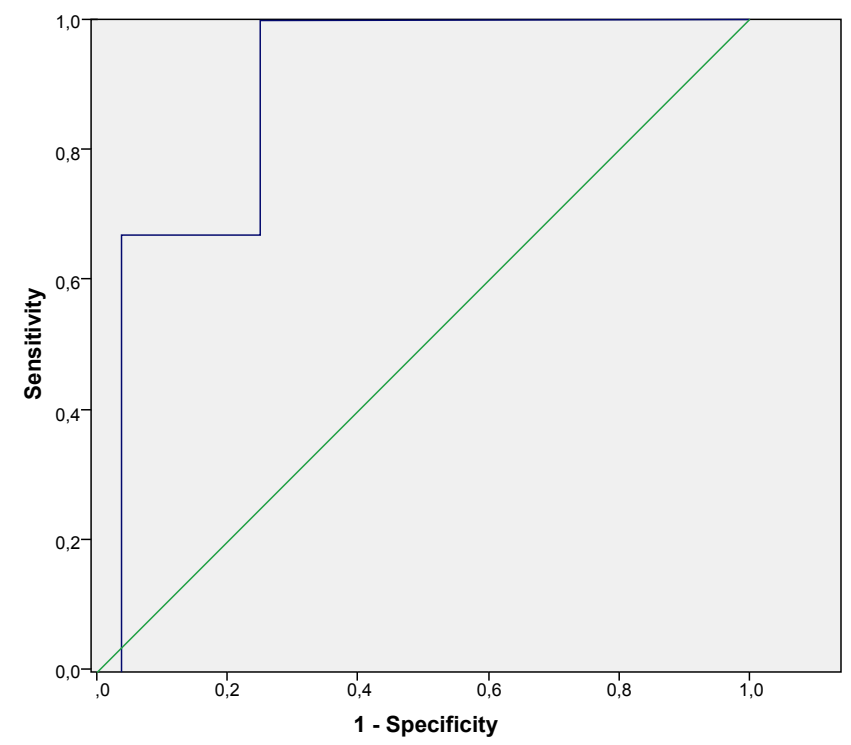

Figure 6: ROC curve for predicting the failure of the conservative management 18 hours after the admission.

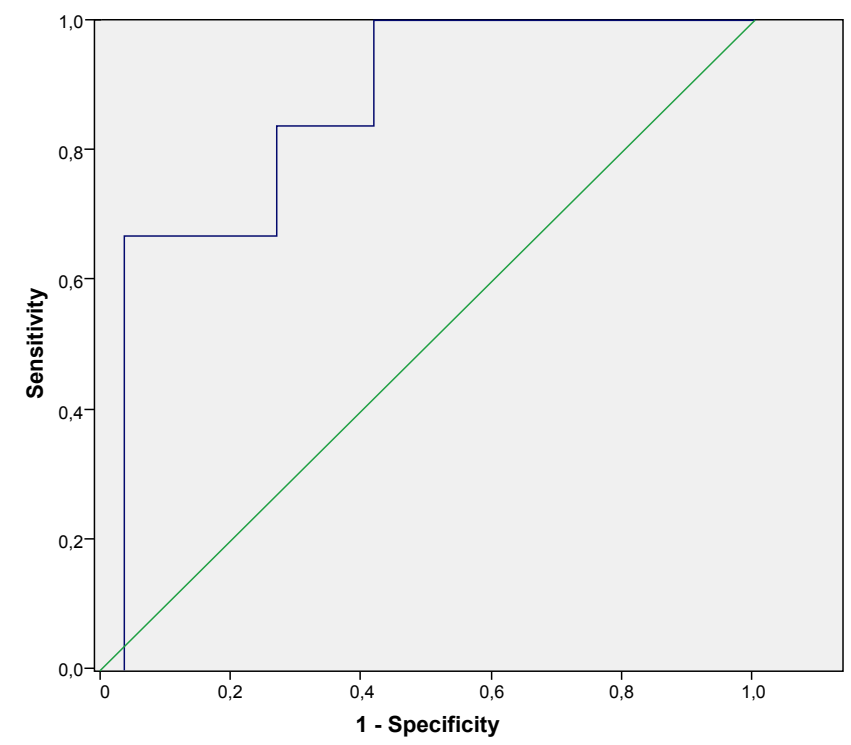

Figure 7: ROC curve for predicting the failure of the conservative management 24 hours after the admission. 


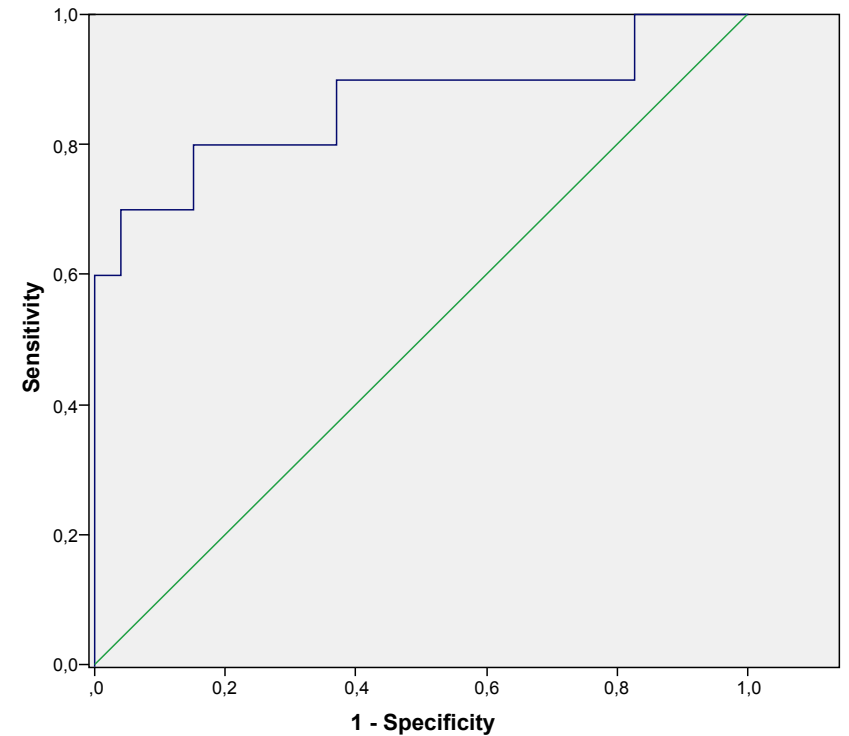

Figure 8: ROC curve for predicting the presence of preoperative ischemia in surgically managed patients.

difficulty to identify the good candidate but his decision should be quick to avoid to pejore the prognosis. To help the clinician some elements are available such as clinical - (abdominal distension, fever); biological - (leukocytes, lactates) and morphological signs (pneumoperitoneum). Nevertheless these signs are imperfect because in our study none of these signs was predictive of the surgery confirming the results of Evennett et al., Gearhart et al. and Delaney et al. [13-15] showing that these "old markers" are not accurate enough. At admission, with a PCT higher than $0.53 \mathrm{ng} / \mathrm{mL}$ the surgeon could decide to operate the patient whereas a PCT between 0.17 and $0.53 \mathrm{ng} / \mathrm{mL}$ involves an aggressive monitoring. Twenty four hours after the admission a PCT higher than $0.27 \mathrm{ng} / \mathrm{mL}$ impose a surgery.

The choice of serum PCT as a biomarker for SBO's management lies on its half life time (24 hours) [16]. As reported by numerous previous works [17-21], in case of inflammatory state (for example SBO), cytokines such as IL6, IL8 and TNFa are released inducing a secretion of PCT but in case of conservative management's success (mainly during the first day after the nasogastric tube suction's beginning) the inflammatory state decreases quickly so the PCT secretion does. Complementary to these works, the data from Nagata et al. [22]; Markogiannakis et al. [23]; Karabulut et al. [24] and Ayten et al. [25] had already presented PCT as a possible biomarker. The strong correlation between PCT and the conservative management failure rate accentuates this proposition.

The difference between the two groups in the study related on chloride has previously been reported [11]. The ion seems be involved in the SBO's management and the disease's severity. Indeed, it is possible that patients requiring surgical management have presented SBO's symptoms longer than the others patients (nausea and vomiting; pain more pronounced). In that case chloride's osmolarity will be modified enhancing PCT's secretion to regulate the calcium's metabolism. The part of chloride in the PCT's secretion is reflected by the ratio PCT SM/ PCT CM. It seems that that ion enhances the production by a factor 2 or 4 (if we consider that no other variable is involved). The increase in the ratio after 36 hours could be due to many factors: the inflammatory state due to the surgical procedure (because in our study the surgery was mainly performed after the 36th hours) [26], the possible infectious phenomenon engendered by the surgery etc.

To validate the use of PCT in this situation, we enrolled patients with acute kidney disease to ensure that kidney disease don't have an impact on this biomarker's kinetics. In deed patients admitted with SBO are frequently aged and could present an altered renal function. Nevertheless, in our population this biological function does not have any effect on PCT's levels. This observation confirms the data of Meisner et al. [27] who reported no difference of PCT in case of renal dysfunction.

This study validates the role of serum PCT as a biomarker of bowel ischemia. Indeed, in our previous study, we showed that PCT was a marker of ischemia with a threshold of $0.57 \mathrm{ng} / \mathrm{mL}$. The confirmation of these data in an independent cohort let us think that PCT could be proposed as a systemic marker of bowel ischemia reflecting the inflammatory state engendering by the obstruction.

\section{Conclusion}

Our work confirms the previous data on the use of PCT as a biomarker in SBO's management. The more predictive time points are at admission, 12 hours and 18 hours after admission to identify patients requiring surgery.

This article has been presented as a poster at the UEG Week 2013 in Berlin

\section{References}

1. Shatila AH, Chamberlain BE, Webb WR (1976) Current status of diagnosis and management of strangulation obstruction of the small bowel. Am J Surg 132: 299-303.

2. Bevan PG (1984) Adhesive obstruction. Ann R Coll Surg Engl 66: 164-169.

3. Vibert E, Regimbeau JM, Panis Y, Lê P, Soyer P, et al. (2002) [Post-operative small bowel obstruction: spiral computed tomography]. Ann Chir 127: 765-770.

4. Menzies D, Ellis H (1990) Intestinal obstruction from adhesions--how big is the problem? Ann R Coll Surg Engl 72: 60-63.

5. Risberg B (1997) Adhesions: preventive strategies. Eur J Surg Suppl : 32-39.

6. Tanaka S, Yamamoto T, Kubota D, Matsuyama M, Uenishi T, et al. (2008) Predictive factors for surgical indication in adhesive small bowel obstruction. Am J Surg 196: 23-27.

7. Schwenter F, Dominguez S, Meier R, Oulhaci-de Saussure W, Platon A, et al (2011) [Acute small bowel obstruction: conservative or surgical treatment?] Rev Med Suisse 7: 1341-1344, 1346-7.

8. Catena F, Di Saverio S, Kelly MD, et al (2011) Bologna Guidelines fo Diagnosis and Management of Adhesive Small Bowel Obstruction (ASBO) 2010 Evidence-Based Guidelines of the World Society of Emergency Surgery. World J Emerg Surg 6:5

9. Moya F, Nieto A, R-Candela JL (1975) Calcitonin biosynthesis: evidence for a precursor. Eur J Biochem 55: 407-413.

10. Assicot M, Gendrel D, Carsin H, Raymond J, Guilbaud J, et al. (1993) High serum procalcitonin concentrations in patients with sepsis and infection. Lancet 341: 515-518.

11. Cosse C, Regimbeau JM, Fuks D, Mauvais F, Scotte M (2013) Serum procalcitonin for predicting the failure of conservative management and the need for bowel resection in patients with small bowel obstruction. J Am Coll Surg 216: 997-1004.

12. Steinbach G, Rau B, Debard AL, Javourez JF, Bienvenu J, et al. (2004) Multicenter evaluation of a new immunoassay for procalcitonin measurement on the Kryptor System. Clin Chem Lab Med 42: 440-449.

13. Evennett NJ, Petrov MS, Mittal A, Windsor JA (2009) Systematic review and pooled estimates for the diagnostic accuracy of serological markers for intestinal ischemia. World J Surg 33: 1374-1383. 
Citation: Cosse C, Sabbagh C, Rebibo L, Grelpois G, Galmiche A, et al. (2014) Kinetics of Procalcitonin in the Management of Small Bowel Obstruction: A Preliminary Report. Surgery Curr Res 4: 184. doi:10.4172/2161-1076.1000184

14. Delaney CP, O’Neill S, Manning F, Fitzpatrick JM, Gorey TF (1999) Plasma concentrations of glutathione S-transferase isoenzyme are raised in patients with intestinal ischaemia. Br J Surg 86: 1349-1353.

15. Gearhart SL, Delaney CP, Senagore AJ, Banbury MK, Remzi FH, et al. (2003) Prospective assessment of the predictive value of alpha-glutathione S-transferase for intestinal ischemia. Am Surg 69: 324-329.

16. Hausfater $P$ (2007) [Procalcitonin measurement in adult clinical practice]. Rev Med Interne 28: 296-305.

17. Baruti Gafurri Z, Pacarizi H, Zhubi B, Begolli L, Topciu V (2010) The importance of determining procalcitonin and $C$ reactive protein in different stages of sepsis. Bosn J Basic Med Sci 10: 60-64.

18. Becker KL, Nylén ES, White JC, Müller B, Snider RH Jr (2004) Clinical review 167: Procalcitonin and the calcitonin gene family of peptides in inflammation, infection, and sepsis: a journey from calcitonin back to its precursors. $\mathrm{J}$ Clin Endocrinol Metab 89: 1512-1525.

19. Carboni GL, Fahrner R, Gazdhar A, Printzen G, Schmid RA, et al. (2008) Comparison of procalcitonin and $\mathrm{CrP}$ in the postoperative course after lung decortication. Eur J Cardiothorac Surg 33: 777-780.

20. Meisner M (2002) Pathobiochemistry and clinical use of procalcitonin. Clin Chim Acta 323: 17-29.

21. Ferrière $F(2000)$ [Procalcitonin, a new marker for bacterial infections]. Ann Biol Clin (Paris) 58: 49-59.
22. Nagata J, Kobayashi M, Nishikimi N, Komori K (2008) Serum procalcitonin (PCT) as a negative screening test for colonic ischemia after open abdominal aortic surgery. Eur J Vasc Endovasc Surg 35: 694-697.

23. Markogiannakis $H$, Memos $N$, Messaris E, Dardamanis D, Larentzakis A, et al. (2011) Predictive value of procalcitonin for bowel ischemia and necrosis in bowel obstruction. Surgery 149: 394-403.

24. Karabulut K, Gül M, Dündar ZD, Cander B, Kurban S, et al. (2011) Diagnostic and prognostic value of procalcitonin and phosphorus in acute mesenteric ischemia. Ulus Travma Acil Cerrahi Derg 17: 193-198.

25. Ayten R, Dogru O, Camci C, Aygen E, Cetinkaya Z, et al. (2005) Predictive value of procalcitonin for the diagnosis of bowel strangulation. World $\mathrm{J}$ Surg 29: 187-189.

26. Barbic J, Ivic D, Alkhamis T, et al (2013) Kinetics of changes in serum concentrations of procalcitonin, interleukin-6, and C- reactive protein after elective abdominal surgery. Can it be used to detect postoperative complications? Coll Antropol 37: 195-201.

27. Meisner M, Schmidt J, Hüttner H, Tschaikowsky K (2000) The natural elimination rate of procalcitonin in patients with normal and impaired renal function. Intensive Care Med 26 Suppl 2: S212-216. 